\title{
Sustentabilidade da produção animal baseada em pastagens consorciadas e no emprego de leguminosas exclusivas, na forma de banco de proteína, nos trópicos brasileiros
}

\author{
Alexandre de Oliveira Barcellos; Allan Kardec Braga Ramos; Lourival Vilela; \\ Geraldo Bueno Martha Junior
}

\section{Introdução}

A produção animal em regime de pastagens, nos trópicos brasileiros, caracteriza-se pelo extrativismo, onde a adoção de tecnologias e uso intensivo em capital restringe-se a um pequeno conjunto de produtores. Tal conduta, na maioria das vezes, determina passivos ambientais relevantes. A perda da capacidade produtiva das pastagens e seus impactos sobre o ambiente e o comprometimento da sustentabilidade da atividade são facilmente percebidos.

A dinâmica das alterações macroeconômicas ocorridas na última década exige dos produtores mudanças de comportamento, pressionados pela necessidade de conferir e assegurar maior produtividade e competitividade a seus sistemas de produção. A sociedade também exerce forte pressão no sentido de mudanças dos modelos atuais de exploração. A preservação dos recursos naturais e da biodiversidade e a mitigação dos impactos relacionados às mudanças climáticas globais, decorrentes das alterações no uso da terra, além da qualidade e segurança dos produtos alimentares, fazem parte da pauta de discussões e ações governamentais.

A intensificação dos sistemas de produção pastoris é apontada como uma das alternativas de exploração sustentável, minimizando a pressão sobre a abertura de novas áreas para produção agropecuária. Esse modelo, entretanto, deverá ser pautado pelo uso eficiente dos recursos físicos, incluindo a recuperação de áreas antropizadas e degradadas, calcada no aporte de conhecimento e de tecnologias poupadoras de insumos.

A competitividade da atividade pecuária brasileira origina-se, em grande parte, da produção de forragem obtida em pastagens cultivadas. Cultivares de espécies forrageiras, para inserção nos diferentes sistemas de produção, são tecnologias que a sociedade brasileira não pode prescindir. As leguminosas forrageiras, em face da capacidade de fixação simbiótica do nitrogênio atmosférico e a sua contribuição para a produção animal, são essenciais para incrementar a produtividade e constituem um caminho na direção da sustentabilidade de sistemas agrícolas e pecuários. Tal assertiva leva em consideração a diversidade de ambientes e sistemas de produção, nos mais de 220 milhões de ha de pastagens nativas e cultivadas, a importância econômica e social da pecuária bovina e seus desafios atuais e futuros para manter-se como uma atividade competitiva.

O conjunto de cultivares de leguminosas forrageiras no mercado é significativo, embora não tenha propiciado a adoção na dimensão pretendida por aqueles envolvidos no desafio de desenvolver e recomendar o seu uso. A pequena tradição no uso de leguminosas forrageiras tropicais, combinada com a limitada adoção, por vezes mal-sucedida, restringe a capacidade de autopromoção da tecnologia. A melhor definição da clientela e ambiente de cultivo (cultivares especialistas), geração e diponibilização de informações sobre seu manejo e benefícios econômicos permanecem como desafios às instituições de pesquisa e transferência de tecnologias para efetiva dispersão e adoção dessa tecnologia.

\section{Produção pecuária em pastagens}

Na última década, a região do Cerrado destacouse como a grande propulsora do agronegócio da carne bovina de corte brasileira e de produção de leite. De acordo com Sano et al. (2008), este rebanho estaria ocupando uma área de pastagens cultivadas de 54,2 milhões de hectares do Cerrado, representando 26,4\% da superfície do bioma. 
Tradicionalmente no Brasil, a pecuária de corte desenvolveu-se como uma atividade pioneira, ligada à ocupação de regiões de fronteira. Na ocupação do Cerrado adotou-se um modelo de produção apoiado na utilização intensa do fator terra e dos recursos naturais (extrativismo), em detrimento da intensificação no uso de capital. A terra desempenhou a função de preservar ativos fixos de reserva de valor (Rezende, 2003), causando demanda e elevação em seu preço. Desse modo, a pecuária (boi e terra) foi encarada como reserva de capital ao invés de uma atividade cuja remuneração econômica pela produção estimulasse seu desenvolvimento e aperfeiçoamento, por meio de investimentos crescentes em tecnologia (Martha Jr. et al., 2006a).

O significativo avanço da pecuária nacional, a partir da década de 1970, ocorreu em um período de grande turbulência política e econômica. A sociedade vivenciou planos econômicos, crises no fornecimento mundial de energia e, internamente, instabilidade política e econômica gerando grande inflação. Essas incertezas encontraram, na atividade pecuária extensiva em pastagens, um ambiente seguro, em função de sua liquidez e baixo risco (Barioni et al., 2003).

Estudos desenvolvidos por Barros et al. (2003) demonstram que a redução no poder de compra da pecuária, entre os anos de 1991 a 2004, foi de sete pontos percentuais, em função da deterioração do poder de troca, entre insumos e produtos comercializáveis e da produtividade. Nesse mesmo período, a atividade agrícola teve incremento de $76 \%$ na capacidade de troca, impulsionada pelo aumento no valor dos produtos e da produtividade. A estabilização da moeda e a competição, gerada por outras atividades econômicas, impõem a necessidade de uso mais intensivo da terra, o que impõem necessidade de profundas mudanças no modelo de exploração pecuária.

Esses problemas da pecuária de corte - termos de troca desfavoráveis e baixos ganhos em produtividade são amplificados pela (Martha Jr. et al., 2006b): 1) conjuntura macroeconômica, como o câmbio valorizado, a taxa de juros elevada, a queda nos preços internacionais das commodities agrícolas e a baixa disponibilidade de crédito com taxas de juros controladas para financiar a produção; 2) pressão pelo uso da terra exercida por outras alternativas agrícolas, como a soja e, mais recentemente, a cana-de-açúcar e oleaginosas para produção de biocombustíveis, que determinam valorização da terra em relação aos produtos da pecuária; 3) expressiva área de pastagens degradadas, que em grande parte determinam a baixa rentabilidade da pecuária de corte "tradicional", em razão da incapacidade de reduzir os custos médios de produção, reflexo direto da progressiva perda de produtividade das pastagens.

Nos moldes atuais de exploração de muitas propriedades de pecuária do Cerrado, o manejo inadequado do sistema solo-planta-animal e o gerenciamento ineficiente da atividade, predispõem à degradação das pastagens, à baixa eficiência bioeconômica e aumento dos impactos negativos sobre o ambiente (erosão, assoreamento de rios, etc.), A partir desse quadro, um contingente crescente de fazendas tradicionais de pecuária se tornará inviável no curto/médio prazo.

A expansão da pecuária de corte em áreas de vegetação nativa de regiões de fronteira continua sendo a estratégia preconizada para aumentar a produção de carne bovina. Esse modelo extrativista de produção pecuária, vigente ao longo das últimas décadas ,deve ser revisto no sentido de adequar-se à nova realidade do setor produtivo. Tal conjuntura demanda aumento da eficiência técnico-econômica da propriedade para assegurar a competitividade e a lucratividade do empreendimento frente às alternativas de uso do solo, de modo sustentável, sem impactar negativamente o ambiente (Martha Jr. et al., 2006a).

Nesse cenário, ao qual periodicamente somam-se novas exigências (rastreabilidade, qualidade, segurança alimentar, exigências sanitárias e ambientais, etc.), o pecuarista deverá conscientizar-se que é necessário elevar a produtividade do "recurso terra" para garantir a rentabilidade do empreendimento, visando a redução do custo médio de produção pela diluição dos custos fixos e dos custos de oportunidade do uso do capital (Barros et al., 2003; Martha Jr. et al., 2006a). Essa proposta é ratificada pela estabilização monetária que, atualmente, em combinação com a alta taxa de juros real e a valorização cambial, diminuem o preço dos ativos imóveis e, portanto, desestimulam a adoção da pecuária apenas como reserva de capital.

A maior produtividade das pastagens pode contribuir para a melhoria da qualidade do solo e para a redução de eventuais impactos sobre o ciclo 
hidrológico, enquanto o maior desempenho por animal pode reduzir a emissão de gases causadores do efeito estufa por unidade de produto produzido (Vilela et al., 2005), o que poderá minimizar possíveis barreiras não tarifárias à produção pecuária brasileira.

Os processos de adoção de tecnologias inovadoras ou menos convencionais, validadas pela pesquisa em sistemas de produção pecuários no Brasil, são lentos e de baixa repercussão. Parte desta constatação deve-se ao perfil dos pecuaristas brasileiros. Villa (2007) identificou um contingente de 1,5 milhões de pecuárias no Brasil. Desses cerca de 200 mil desenvolvem a atividade de forma semi-tecnificada. Apenas 20 mil são caracterizados como empresários do setor e 2 mil são considerados pecuaristas líderes. Constata-se, portanto, a necessidade de um grande esforço, suportado por novos modelos de transferência de tecnologia e capacitação técnica visando modificar modelo de exploração atualmente implantado.

O uso de fertilizantes e corretivos pelos pecuaristas é muito limitado, apesar de ser uma maneira efetiva de repor nutrientes no sistema e, potencialmente, garantir a sustentabilidade do sistema de produção. O consumo de fertilizantes em pastagens, nos últimos anos, tem variado de 400 a 500 mil toneladas. Considerando que apenas a área de pastagem cultivada - de aproximadamente 140 milhões de hectares - recebe adubação, ter-se-ia que a adubação anual de pastagem seria da ordem de 2,9 a 3,6 kg/ha de fertilizantes NPK. Essa reposição insuficiente de nutrientes certamente é um dos principais fatores que explica o crescente processo de degradação das pastagens.

Nos sistemas intensivos de criação os gastos diretos com fertilizantes podem representar mais de 60 \% do custo de produção, implicando ainda custos agregados com transporte, armazenamento, aplicação, aquisição de animais (pela maior lotação) e outros insumos, além de uma eficiente gestão da produção e utilização da forragem produzida.

As leguminosas podem contribuir, associada a outras tecnologias, para minimizar os reflexos diretos e indiretos desse cenário, em escala local e nacional, por conta dos distintos serviços que, potencialmente, podem desempenhar, não se restringindo apenas às cadeias de produção de carne e leite.

\section{Cultivares de leguminosas tropicais para uso em pastagens}

A adoção de leguminosas na formação de pastagens, em consórcio ou exclusivas, é orientada pela escolha do cultivar mais adequado às condições ambientais, à natureza da exploração, à capacidade de intervenção e à disponibilidade de recursos, dentre outros. Embora a tomada de decisão seja semelhante a empregada na escolha de uma gramínea forrageira, existe uma resistência maior à leguminosa por parte de técnicos e produtores, em função dos riscos de insucesso e dos custos envolvidos. Parte dessa questão deve-se ao maior conhecimento e informações disponibilizadas às gramíneas forrageiras e de um comércio agressivo de comercialização de suas sementes.

Algumas das informações mais relevantes sobre as espécies e cultivares de maior importância atual, são apresentadas nos Quadros 1 e 2. Novos cultivares de leguminosas são necessários para usos múltiplos, os quais também contribuiriam para aumentar a diversidade genética das áreas com pastagens, hoje bastante homogêneas.

Dentre os cultivares ou gêneros botânicos com maior estoque de informações, destacam-se os estilosantes (Stylosanthes spp.), o amendoim forrageiro (Arachis pintoi) e a leucena (Leucaena spp.), por serem os mais cultivados e/ou mais promissores.

Conhecendo as características adaptativas dos cultivares (solo e clima, principalmente), a capacidade de retenção de folhas na seca e a distribuição da produção ao longo do ano, diversas combinações de pastagens consorciadas poderão existir visando o melhor suprimento em quantidade e qualidade ao longo do ano, como por exemplo: pastagens consorciadas de Leucaena nas águas; pastagens de Cajanus na transição águas-seca e pastagens de Stylosanthes na época seca.

Dentre as gramíneas, o Andropogon gayanus cv. Planaltina ou cv. Baetí é o que apresenta maior facilidade de consorciação com as leguminosas herbáceas. A Brachiaria brizantha cv. Marandu tem se mostrado a gramínea mais agressiva, sendo difícil a estabilidade dos pastos consorciados com leguminosas herbáceas ou de porte baixo. Nesse caso, tem-se recomendado o consórcio com leguminosas arbustivas ou a utilização de bancos de proteínas de leguminosas herbáceas. Em Brachiaria, o cultivar Basilisk (B. decumbens) tem sido a gramínea mais adequada para o consórcio com leguminosas herbáceas no Cerrado. 
Quadro 1- Algumas características morfológicas e adaptativas de cultivares de leguminosas forrageiras tropicais

\begin{tabular}{|c|c|c|c|c|c|c|c|c|}
\hline Espécie & Cultivar & $\begin{array}{c}\text { Porte e } \\
\text { hábito de } \\
\text { crescimento }\end{array}$ & $\begin{array}{l}\text { Exigência } \\
\text { fertilidade do } \\
\text { solo (calagem } \\
\text { e adubação) }\end{array}$ & $\begin{array}{c}\text { Dificuldade } \\
\text { no manejo } \\
\text { (em consórcio) }\end{array}$ & $\begin{array}{c}\text { Resistência } \\
\text { à pragas e } \\
\text { doenças }\end{array}$ & $\begin{array}{c}\text { Tolerância ao mau } \\
\text { manejo } \\
\text { (superpastejo) e } \\
\text { persistência }\end{array}$ & $\begin{array}{c}\text { Produção } \\
\text { de sementes }\end{array}$ & $\begin{array}{c}\text { Valor } \\
\text { alimentício }\end{array}$ \\
\hline \multirow{2}{*}{$\begin{array}{c}\text { Arachis } \\
\text { pintoi }\end{array}$} & Amarillo & \multirow{2}{*}{$\begin{array}{l}\text { Herbáceo, } \\
\text { prostrado, } \\
\text { estolonífero }\end{array}$} & \multirow{2}{*}{ Média } & \multirow{2}{*}{ Baixa } & $\begin{array}{c}\text { Média - } \\
\text { Cercosporiose }\end{array}$ & \multirow{2}{*}{ Alta } & Média & \multirow{2}{*}{$\begin{array}{l}\text { Alto, com alta } \\
\text { palatabilidade }\end{array}$} \\
\hline & Belmonte & & & & $\begin{array}{c}\text { Alta - } \\
\text { Cercosporiose }\end{array}$ & & $\begin{array}{c}\text { Nula ou } \\
\text { desprezível }\end{array}$ & \\
\hline $\begin{array}{c}\text { Calopogonium } \\
\text { mucunoides }\end{array}$ & Comum & $\begin{array}{l}\text { Herbáceo, } \\
\text { volúvel }\end{array}$ & Baixa & Média & Alta & Alta & Alta & Médio \\
\hline $\begin{array}{c}\text { Cajanus } \\
\text { cajan }\end{array}$ & Super N & $\begin{array}{l}\text { Subarbusto, } \\
\text { ereto }\end{array}$ & Baixa & Média & Alta & Média & Alta & Médio \\
\hline $\begin{array}{c}\text { Leucaena } \\
\text { leucocephala }\end{array}$ & Cunningham & $\begin{array}{l}\text { Arbustivo- } \\
\text { arbóreo, ereto }\end{array}$ & Alta & Alta & $\begin{array}{c}\text { Ataque de } \\
\text { formigas e } \\
\text { cupins no } \\
\text { estabelecimento } \\
\end{array}$ & Média & Alta & $\begin{array}{l}\text { Alto, com alta } \\
\text { palatabilidade }\end{array}$ \\
\hline $\begin{array}{c}\text { Stylosanthes } \\
\text { guianensis }\end{array}$ & Mineirão & $\begin{array}{l}\text { Herbáceo- } \\
\text { subarbustivo, } \\
\text { ereto }\end{array}$ & Baixa & Alta & $\begin{array}{c}\text { Alta - } \\
\text { Antracnose }\end{array}$ & Baixa & Baixa & Médio \\
\hline $\begin{array}{l}\text { Stylosanthes } \\
\text { macrocephala }\end{array}$ & Pioneiro & $\begin{array}{l}\text { Herbáceo, } \\
\text { ereto }\end{array}$ & Baixa & Média & $\begin{array}{c}\text { Média - } \\
\text { Antracnose }\end{array}$ & Baixa & Alta & Médio \\
\hline $\begin{array}{l}\text { Stylosanhtes spp. } \\
(\text { S. capitata }+ \\
\text { S. macrocephala) }\end{array}$ & $\begin{array}{l}\text { Campo } \\
\text { Grande }\end{array}$ & $\begin{array}{l}\text { Herbáceo, } \\
\text { ereto }\end{array}$ & Baixa & Média & $\begin{array}{c}\text { Alta - } \\
\text { Antracnose }\end{array}$ & Baixa & Alta & Médio \\
\hline $\begin{array}{c}\text { Neonotonia } \\
\text { wightii }\end{array}$ & $\begin{array}{l}\text { Clarence, } \\
\text { Cooper, } \\
\text { Tinaroo }\end{array}$ & $\begin{array}{l}\text { Herbáceo, } \\
\text { volúvel }\end{array}$ & Alta & Média & Média - Oídio & Baixa & Média & Alto \\
\hline
\end{tabular}

Quadro 2- Principais aspectos positivos e negativos de cultivares de leguminosas forrageiras tropicais

\begin{tabular}{|c|c|c|c|}
\hline Espécie & Cultivar & Aspectos positivos & Aspectos negativos \\
\hline \multirow{2}{*}{$\begin{array}{c}\text { Arachis } \\
\text { pintoi }\end{array}$} & Amarillo & $\begin{array}{c}\text { Qualidade da forragem; persistência; tolerante ao encharcamento } \\
\text { do solo; boa capacidade de consorciação. Também utilizada como } \\
\text { planta de cobertura }\end{array}$ & $\begin{array}{l}\text { Baixa retenção de folhas na seca; oferta e preço de } \\
\text { sementes. Baixa produtividade em vários locais }\end{array}$ \\
\hline & Belmonte & Idem cv. Amarillo & $\begin{array}{l}\text { Baixa retenção de folhas na seca. Propagação apenas por } \\
\text { mudas. }\end{array}$ \\
\hline $\begin{array}{l}\text { Calopogonium } \\
\text { mucunoides }\end{array}$ & Comum & $\begin{array}{c}\text { Oferta de sementes no mercado; boa capacidade de ressemeadura } \\
\text { natural; facilidade de estabelecimento. Plantio pode ser associado } \\
\text { com arroz. Também utilizada como planta de cobertura }\end{array}$ & $\begin{array}{l}\text { Qualidade da forragem; baixa retenção de folhas na } \\
\text { época seca; baixa aceitabilidade/palatabilidade no } \\
\text { período chuvoso }\end{array}$ \\
\hline $\begin{array}{l}\text { Leucaena } \\
\text { leucocephala }\end{array}$ & Cunningham & \begin{tabular}{|c|} 
Qualidade da forragem; alta palatabilidade; capacidade de \\
consorciação; alta produtividade na estação chuvosa e, em locais \\
de alta fertilidade natural, boa produção na seca; oferta de \\
sementes no mercado. Alta sobrevivência depois de estabelecido.
\end{tabular} & $\begin{array}{l}\text { Baixa tolerância a solos ácidos, afetando a retenção de } \\
\text { folhas na seca. Não pode ser o único volumoso na dieta, } \\
\text { devido a presença de mimosina (fator anti-nutricional). }\end{array}$ \\
\hline $\begin{array}{c}\text { Pueraria } \\
\text { phaseoloides }\end{array}$ & Comum & $\begin{array}{c}\text { Capacidade de consorciação com gramíneas agressivas; alta } \\
\text { qualidade da forragem, adaptada a áreas úmidas; pouco atacada } \\
\text { por pragas e doenças; boa ressemeadura natural }\end{array}$ & Baixa retenção de folhas na seca \\
\hline $\begin{array}{l}\text { Stylosanthes } \\
\text { macrocephala }\end{array}$ & Pioneiro & $\begin{array}{c}\text { Adaptados a solos arenosos; bom produtor de sementes com boa } \\
\text { ressemeadura natural; capacidade de consorciação com } B \text {. } \\
\text { decumbens e Andropogon gayanus; }\end{array}$ & $\begin{array}{c}\text { Baixa retenção de folhas na seca;-atualmente sem oferta } \\
\text { de sementes no mercado. }\end{array}$ \\
\hline $\begin{array}{l}\text { Stylosanhtes spp. } \\
\quad(\text { S. capitata }+ \\
\text { S. macrocephala) } \\
\end{array}$ & $\begin{array}{l}\text { Campo } \\
\text { Grande }\end{array}$ & $\begin{array}{l}\text { Adaptação a solos arenosos; persistência sob pastejo; } \\
\text { ressemeadura natural; baixo preço da sementes; tolerância à } \\
\text { antracnose alta ou média, dependendo do local de cultivo. }\end{array}$ & Baixa retenção de folhas na seca \\
\hline $\begin{array}{l}\text { Neonotonia } \\
\text { wightii }\end{array}$ & $\begin{array}{l}\text { Clarence, } \\
\text { Cooper, } \\
\text { Tinaroo }\end{array}$ & $\begin{array}{l}\text { Alto valor alimentício; capacidade de consorciação com } \\
\text { gramíneas mais agressivas; boa ressemeadura natural }\end{array}$ & \begin{tabular}{|c|} 
Não validada em várias regiões do Cerrado; \\
possibilidade de ser invasora em áreas de integração \\
pecuária lavoura; baixa oferta de sementes no mercado; \\
baixa retenção de folhas na seca
\end{tabular} \\
\hline
\end{tabular}


No ecossistema de Mata Atlântica, a consorciação de B.humidicola com o amendoim forrageiro (Arachis pintoi cv. Belmonte) ou com o Desmodium ovalifolium cv. Itabela tem apresentado grande estabilidade. A Pueraria phaseoloides (kudzu tropical) assume grande expressão em consórcio com diversas gramíneas na região amazônica.

A leucena (Leucaena leucocephala) e a sojaperene (Neonotonia wightii) demandarão solos de maior fertilidade. Assim como o amendoim-forrageiro (A.pintoi), estas leguminosas podem ser utilizadas em sistemas um pouco mais intensivos.

$\mathrm{O}$ amendoim forrageiro e a leucena apresentam maior valor nutritivo e são avidamente consumidos pelos animais em qualquer época do ano. São leguminosas que em consórcio têm grande impacto na produção animal quase que exclusivamente no período das águas, porque com o pastejo intenso nas águas, não haverá oportunidade de acúmulo de forragem para época seca.

Muitas das combinações possíveis entre gramíneas e leguminosas não foram validadas, principalmente quando envolvem os cultivares de lançamento mais recente (e.g. Brachiaria brizantha cv. Xaraés e cv. Piatã; Panicum spp cv. Massai; estilosantes cv. Campo Grande). Algumas dessas combinações poderão ser exitosas, a julgar pela performance já conhecida dos cultivares em outras situações de maior desafio.

\section{Contribuição das leguminosas no aporte de nitrogênio}

Os fertilizantes nitrogenados têm como principal insumo para a fabricação a energia do gás natural (80 \% do custo), derivado da exploração de petróleo (Tisdale et al., 1985). Para a produção industrial (30 a $350 \mathrm{~atm})$ de $1 \mathrm{~g}$ de amônia são gastos $39 \mathrm{~kJ}$ (=10,83 Wh) de energia oriunda de combustível fóssil (Sittig, 1979), ao passo que na fixação biológica (1 atm) são gastos cerca de 36-44 kJ de energia renovável (solar) na forma de ATP (35-40 ATP/ $\mathrm{N}_{2}$ ). Num mundo com demanda crescente por energia e por processos menos dependentes de combustíveis fósseis, se modificada a fonte de energia e/ou implementadas taxações e o controle de emissões, os preços dos fertilizantes se elevarão irremediavelmente, limitando ainda mais as oportunidades de uso em sistemas extensivos de criação. Como ilustração, o aporte de $30 \mathrm{~kg} / \mathrm{ha} /$ ano de N num pasto consorciado proporcionaria uma economia de energia de aproximadamente $400 \mathrm{kWh} / \mathrm{ha}$ somente com a fabricação do equivalente em amônia.

A fixação biológica do nitrogênio (FBN) é a principal via de inclusão do $\mathrm{N}$ atmosférico no sistema solo-planta (170 x $10^{9} \mathrm{~kg}$ de N/ano) (Peoples e Craswell, 1992), sendo as leguminosas verdadeiras biofábricas consumidoras de energia limpa e renovável cuja linha de produção é de interesse para muitos sistemas de produção animal e vegetal. Em geral, nas leguminosas fixadoras de $\mathrm{N}$, cerca do $75 \%$ do $\mathrm{N}$ é oriundo da fixação biológica (Tisdale et al., 1985). Em particular, leguminosas forrageiras tropicais podem fixar de 2 a $183 \mathrm{~kg} / \mathrm{ha} / \mathrm{ano}$ de $\mathrm{N}$, sendo que a FBN responde por 70 a $94 \%$ do $\mathrm{N}$ existente na parte área (Thomas, 1995). A quantidade de $\mathrm{N}$ fixado varia com a espécie e com as condições do ambiente (sentido amplo). Acidez do solo, salinidade, deficiências ou excesso de minerais, estresse hídrico, variações na temperatura, a quantidade de $\mathrm{N}$ inorgânico no solo, pragas e doenças acabam por afetar a FBN. Quanto mais pobre em $\mathrm{N}$ for o solo, maior será a proporção do $\mathrm{N}$ da planta derivado da fixação biológica (\% NDFB), que se situará acima de $85 \%$. Pastagens de puerária (Pueraria phaseoloides) apresentaram 75 a $92 \%$ do NDFB, ao passo que em Stylosanthes spp. o NDFB representou de 60 a $90 \%$ do $\mathrm{N}$ da planta ao longo de três anos (2 a $84 \mathrm{~kg} / \mathrm{ha} / \mathrm{ano}$ de $\mathrm{N}$ fixado) (Peoples e Craswell, 1992). Vallis e Gardener (1985) registraram pequena variação/diferença na \% NDFB entre acessos de Stylosanthes na Austrália com a idade da pastagem (até 6 anos), indicando que a \% NDFB é relativamente estável com o tempo. Ressalte-se que adubação fosfatada de manutenção foi adotada. A maioria das estimativas de fixação é feita em stands puros, o que superestima as quantidades fixadas num regime de consórcio, porém poderá subestimar a eficiência da aquisição do $\mathrm{N}$ atmosférico (\%NDFB). Apesar disso, pelos valores apresentados, depreende-se que o aporte de nitrogênio pode ser substancial em relação à grande maioria dos sistemas de produção de bovinos.

A liberação do nitrogênio fixado biologicamente responderá em grande parte pela manutenção da produtividade da gramínea. As transferências do nitrogênio ocorrerão abaixo e acima da superfície do 
solo, diretamente ou indiretamente para a planta mais próxima, seja pela excreção de $\mathrm{N}$ na rizosfera da leguminosa, pela decomposição de raízes e nódulos, pela conexão por micorrizas das raízes da gramínea com aquelas da leguminosa, ou ainda pela ação da fauna do solo sobre raízes e nódulos da leguminosa. Já na superfície do solo, ocorrerá pela decomposição da liteira (serapilheira) de folhas na superfície, pela lixiviação de compostos nitrogenados do dossel da pastagem e com as perdas foliares de amônia, passível de absorção pela gramínea. Haverá ainda a ciclagem do $\mathrm{N}$ pela excretas (fezes e urina) dos animais em pastejo, que é a via mais rápida do que a da serapilheira Cerca de 75 a $95 \%$ do $\mathrm{N}$ ingerido pelo animal, retorna à superfície do solo como excreta, sendo que 50 a $80 \%$ dessa excreção é via urina. Apesar da importância, essa via é menos eficiente para a ciclagem por causa da distribuição irregular das excreções (cobrindo de $30 \mathrm{a}$ 40 \% da área com maiores lotações) e das perdas por volatilização e lixiviação, uma vez que o aporte de $\mathrm{N}$ no local de excreção atinge o equivalente a 500-1500 kg/ha de $\mathrm{N}$-uréia. A distribuição e o estoque de $\mathrm{N}$ nas excretas aumenta com a intensidade do pastejo e com o teor de $\mathrm{N}$ na dieta. Da mesma forma, a excreção via urina será aumentada quanto maior for o valor nutritivo da forragem (Ledgard e Steele, 1992).

Em pastagens de Brachiaria decumbens na Colômbia, apenas $10 \%$ do $\mathrm{N}$ da urina foi recuperado pelas plantas (Fisher et al., 1997). Altas temperaturas e o regime hídrico afetam substancialmente a eficiência de recuperação na regiões tropicais. Para o N das fezes, as perdas nas condições tropicais são bem menores, uma vez que uma pequena fração (20-25 \%) encontra-se na forma solúvel e os teores são originalmente baixos em pastagens exclusivas com gramíneas (Fisher et al., 1997). Nesse caso, a partição do $N$ entre urina e fezes se equivale. Nos pastos consorciados, a tendência é de elevação da excreção de $\mathrm{N}$ na urina, particularmente nas águas.

Altas taxas de transferência de $\mathrm{N}$ não são desejáveis porque afetam a estabilidade da consorciação, uma vez que favorecem o crescimento da gramínea, diminuem o crescimento e a FBN pela leguminosa.

Nos sistemas extensivos, a eficiência de colheita da forragem sob pastejo não é elevada (30-40\%). Assim, a maior parte do $\mathrm{N}$ da parte área será ciclada por meio da serapilheira e quanto menor a intensidade do pastejo e da utilização da pastagem, maior será o estoque de $\mathrm{N}$ na serapilheira. No caso de pastos exclusivos de gramínea e dada a menor qualidade per se do material senescido, é apreciável a quantidade de $\mathrm{N}$ que permanece imobilizada e que reciclará mais lentamente. Cantarutti e Boddey (1997) apontaram esse processo como responsável pelo declínio ou como limitante na produtividade das pastagens tropicais. Nos pastos consorciados, como a composição da serapilheira é melhor e mais equilibrada, a ação da fauna e do microbiota do solo é favorecida, acelerando a liberação de nitrogênio para utilização pelas plantas em crescimento. Nesse processo, a leguminosa forrageira e o ambiente de cultivo determinam as quantidades, as taxas e os fluxos do N. Na Colômbia, o tempo necessário para o desaparecimento de metade da liteira depositada (meia-vida) em pastos consorciados variou de 26 a 171 dias nas águas, sendo praticamente nulo o desaparecimento na época seca. A recuperação do $\mathrm{N}$ da serapilheira pela gramínea (Brachiaria) variou de 1 a 14 $\%$, ao passo que a recuperação no sistema solo-planta variou de 50 a $85 \%$, sugerindo a ocorrência de perdas de N por volatilização (Fisher et al., 1997). Diferenças marcantes entre pastagens puras e consorciadas de Desmodium ovalifolium cv. Itabela e em pastagens de Arachis pintoi foram relatadas na revisão efetuada por Pereira (2002). A meia-vida da serapilheira do amendoim forrageiro é bem menor que a de outras leguminosas, dada a qualidade da liteira (relação C:N; lignina; tanino). Face à imobilização dos nutrientes na serapilheira, Fisher et al. (1997) estimaram que a participação da leguminosa na pastagem deve ser acima de $30 \%$ (em massa).

A atividade biológica do solo em pastos consorciados é favorecida, contribuindo para a velocidade de ciclagem e a redução de perdas pela incorporação dos resíduos. Em pastos de B.decumbens consorciados ou não com centrosema foram encontrados, respectivamente, 35 e 17 insetos por placa de fezes que cobriam uma área maior de solo nas pastagens consorciadas. Também, a população de minhocas na pastagem consorciada foi o dobro da registrada na pastagem exclusiva de gramínea e cinco vezes maior que a observada na pastagem nativa (Fisher et al., 1997). Além do aporte de $\mathrm{N}$ e do aumento da atividade biológica, pastagens consorciadas podem 
melhorar a estrutura do solo, a capacidade de armazenamento de água do solo, aumentar o poder tampão do solo (pelo aporte de matéria orgânica) e quebrar ciclo de patógenos, contribuindo decisivamente para um maior período produtivo da pastagem.

A continuidade dos estudos sobre o aporte de nitrogênio originário das leguminosas, uma vez constatado seu potencial, devem seguir no sentido da validação dos impactos econômicos sobre os sistemas de produção. Novas perspectivas de uso de nitrogênio mineral em gramíneas forrageiras, associada com leguminosas de porte arbóreo, sinalizam para possibilidade de viabilizar, economicamente, o uso de nitrogênio e de intensificar a produção animal pela melhoria na qualidade da dieta (Barcellos, 2006). As respostas obtidas ainda dão margem à possibilidade de aumento na eficiência do uso da proteína pela adição de fontes suplementares de energia na dieta animal.

\section{Contribuição das leguminosas para o seqüestro de carbono e mitigação dos gases de efeito estufa}

Os sistemas de produção animal convivem, permanentemente, com o ônus dos impactos gerados pela atividade e sua relação com o aumento na emissão de gases de efeito estufa (GEE). As mudanças no uso da terra, geradas pela expansão da pecuária e implantação de novas pastagens, a produção de metano, de origem metabólica, e a emissão de oxido nitroso, pelo uso de fertilizantes nitrogenados, são consideradas as principais fontes de origem das emissões. A dimensão do rebanho brasileiro associado a extensa área de pastagens colocam em evidência a importância e os impactos dessa atividade como fonte emissora de GEE ou como dreno, a depender do manejo imposto (Soussana et al., 2007).

As gramíneas forrageiras em condições adequadas de produção de massa vegetal, são capazes de seqüestrar significativas quantidades de carbono fixando-o no solo na forma orgânica, tanto em sistemas de pastagens puras (Humphreys, 1994; Cerri, et al., 2007) como em sistemas rotacionados de grão com pastagens (Sousa, 1997, ; Fornara, et al., 2008 Salton et al., 2008). A capacidade de acúmulo, em sistemas exclusivos de gramíneas, é limitada pela deficiência de nutrientes no solo e, especialmente, e pela baixa disponibilidade de nitrogênio em função da baixa taxa de mineralização.

A leguminosa forrageira, conforme discutido em tópicos anterior, constitui-se em uma das fontes importantes de nitrogênio, possibilitando incrementar sua disponibilidade no sistema solo-planta-animal. Dessa forma, poderiam ser obtidas significativos aumentos na fixação de carbono ao solo, bem como reduzir a emissão de gases causadores do efeito estufa por unidade de produto produzido.

Estudos comparativos em áreas de pastagens exclusivas de gramíneas e consorciadas com leguminosas, indicaram aumentos significativos nos estoques de carbono em presença da leguminosa. Shunk, et al. (2004) em pastagens pura de Brachiaria e consorciada com a cv. Campo Grande, detectaram na camada superficial do solo $(10 \mathrm{~cm})$ valores superior de C superando em 1,4 t/ha a quantidade observada em pastos puros. Trabalhos desenvolvidos com outras espécies de gramíneas e leguminosas tropicais evidenciam incrementos de carbono no solo da ordem de $20 \%$ (Tarré et al., 2007), evidenciando a importante de sua atuação e reforçando a necessidade de maiores os estudos de seus impactos no processos de seqüestro de carbono.

O valor nutricional da forragem tem reflexos diretos sobre a produtividade animal. As leguminosas forrageiras, participando da dieta animal, contribuem para incrementar o ganho em peso bem como aportam maior quantidade de nutrientes à dieta e propiciam melhoria de parâmetros ruminais podendo reduzir a metanogênese (Montenegro, et al., 2000). Compostos associados às leguminosas forrageiras, como os taninos, podem ter ação benéfica na produção de metano. Espécies como Leucaena, cujas concentrações de taninos condensados é elevada, propiciaram a redução na emissão de metano (Possenti, 2006).

Os estudos relacionados ao papel das leguminosas como componente no processo de mitigação dos GEE ainda são pequenos, especialmente em ambientes tropicais. Os benefícios das leguminosas no incremento na produção primária de forragem, no desempenho animal e nos impactos sobre as propriedades químicas e biológicas do solo reforçam a necessidade de ampliação desses estudos. 


\section{Leguminosas forrageiras e seu valor para produção animal}

A maioria das leguminosas tropicais apresenta baixa aceitabilidade pelos bovinos na estação chuvosa. Assim, o efeito mais marcante da leguminosa de baixa palatabilidade na dieta animal ocorre a partir do período de transição das águas para a seca, quando as condições ambientais para crescimento e a qualidade da forragem da gramínea são bastante críticas, limitando o consumo. Todavia, nessas situações em que a gramínea apresenta menor valor nutritivo, o desempenho animal (g/dia) responde linearmente ao aporte de proteína na dieta (Humphreys, 1991). Além do maior teor de proteína bruta, em geral, as leguminosas tropicais apresentam menor proporção de parede celular, e a digestibilidade da matéria seca é semelhante ou maior que a registrada nas gramíneas tropicais, para um mesmo estádio de desenvolvimento e condição de cultivo. No entanto, as principais vantagens decorrem da menor taxa de declínio nos teores de proteína bruta e da digestibilidade com a idade e, principalmente, do baixo tempo de retenção da forragem no rúmen, conferido pelo formato e o arranjo das células e a menor proporção de tecido vascular, apesar dos maiores teores de lignina da leguminosa. Como conseqüência da maior taxa de esvaziamento do rúmen, tem-se a elevação do consumo de forragem que, na maioria das vezes, supera os benefícios oriundos do suprimento de proteína sobre o desempenho animal (Norton e Poppi, 1995). A menor taxa de decréscimo no valor nutritivo é oportuna e necessária para as leguminosas de menor palatabilidade, uma vez que permanecem em crescimento livre por um longo período.

Em relação aos minerais, a diferença mais marcante entre gramíneas e leguminosas tropicais reside no maior teor de cálcio na forragem da leguminosa, que pode ser 3 vezes maior (1,2 vs. 0,4 \%) (Norton e Poppi, 1995).

Trabalhos desenvolvidos por Ladeira et al. (2002) permite comparar a composição química e valor nutricional de de algumas leguminosas (Tabela 1). Destacam-se dentre as espécies estudadas o Arachis pintoi pela digestibilidade aparente da matéria seca, teores de proteína bruta e NDT, quando comparados com alfafa. A leucena apresenta características valiosas como teor de proteína bruta e baixos teores de fibra. Já o estilosantes reúne vantagens quanto a composição de aminoácidos essenciais. Observaram-se valores maiores desta fração no estilosantes em relação a alfafa, destacando-se os elevados teores de metionina e sua baixa degradabilidade. Esta constatação tem relevância na dieta animal onde existe carência desse aminoácido essencial. Na alimentação de animais lactantes e de alta produção a metionina é o aminoácido mais limitante ( Blum et al. 1999).

As leguminosas tropicais também apresentam taninos em maior (e.g. Desmodium, Cajanus) ou menor grau (Arachis, Neonotonia, Centrosema), que interferem na palatabilidade (diminuída), no risco de timpanismo (reduz), na digestão e no aproveitamento da proteína e dos carboidratos da forragem. No entanto, dependendo da natureza e da concentração destes taninos na forragem, algumas vantagens podem ser obtidas, especialmente em dietas ricas em proteína (e.g Leucaena pastejada nas águas). Caso essa proteína não fosse em parte complexada, seria precariamente aproveitada pelo animal, uma vez que a alta taxa de degradação no rúmen não estaria sincronizada com o suprimento de energia. Então, ocorreriam perdas de N, excretado na forma de uréia, inclusive com algum custo energético. Poppi e McLennan (1995) estimaram que as perdas de proteína ingerida já ocorreriam em dietas cujo teor de PB estivesse acima de 9,4-11,3\%, situação bastante comum em muitas pastagens.

\section{Leguminosas forrageiras e seu impacto sobre a produtividade animal}

Ampliar a capacidade de produção por animal, melhorando o valor nutritivo da forragem, representa alternativa de menor impacto quanto à necessidade de investimentos e de forte apelo ambiental e produtivo.

O nitrogênio suprido pela leguminosa dá suporte à produtividade de forragem e amplia a vida útil da pastagem. Leguminosas bem adaptadas, tardias e resistentes à seca poderão ainda diminuir a estacionalidade da produção de forragem verificada em pastos exclusivos de gramíneas.

Pela quantidade de $\mathrm{N}$ aportado pela leguminosa, depreende-se que os pastos consorciados não podem dar suporte a altas taxas de lotação, independentemente das limitações morfofisiológicas das leguminosas forrageiras. Assim, a contribuição direta das 
leguminosas para a produção animal decorre da mudança no perfil quantitativo e qualitativo da dieta, com o efeito mais marcante sobre o desempenho animal (produção/animal/dia), que guarda uma relação inversa com a taxa de lotação (animais/áreas) e direta com a oferta de forragem (kg de forragem/animal/dia). Explora-se, então, o mérito genético do animal.

Tabela 1. Coeficiente de digestibilidade aparente (\%) da matéria seca, composição química, NDT, teores de energia e proporção de aminoácidos essenciais (AME) dos fenos de Arachis pintoi, estilosantes (Stylosanthes guianensis), soja perene (Glycine wightii), leucaea (Leucaena leucocephala) e alfafa (Medicago sativa).

\begin{tabular}{|c|c|c|c|c|c|}
\hline Item & Arachis pintoi & $\begin{array}{l}\text { Stylosanthes } \\
\text { guianensis }\end{array}$ & Glycine wightii $^{2}$ & Leucaena leucocephala ${ }^{3}$ & Medicago sativa $^{4}$ \\
\hline Coef. Digestib. Aparente & 64,4 & 49,2 & 44,3 & 55,6 & 59,9 \\
\hline Matéria Seca & 88,1 & 91,6 & 90,1 & 92,7 & 90,0 \\
\hline Matéria Orgânica $^{5}$ & 95,0 & 95,6 & & 88,2 & 93,3 \\
\hline Proteína Bruta ${ }^{5}$ & 14,3 & 9,8 & 12,3 & 16,3 & 17,0 \\
\hline Extrato Etéreo $^{5}$ & 1,8 & 4,7 & & & \\
\hline Carboidratos(CHO) $^{5}$ & 79,9 & 81,0 & 52,0 & & \\
\hline Fibra Det. Neutro $^{5}$ & 52,5 & 63,7 & & 43,3 & 53,4 \\
\hline CHO não Fibrosos ${ }^{5}$ & 26,5 & 17,3 & 40,4 & & 41,5 \\
\hline Fibra Det. Ácido $^{5}$ & 35,8 & 50,1 & 19,3 & 33,8 & \\
\hline Celulose $^{5}$ & 38,3 & 26,3 & 11,6 & 24,5 & \\
\hline Hemicelulose $^{5}$ & 16,7 & 13,6 & 13,9 & 9,5 & \\
\hline Lignina $^{5}$ & 11,2 & 11,8 & & 14,4 & 12,9 \\
\hline $\mathrm{NDT}^{5}$ & 66,4 & 53,7 & & & \\
\hline Energia Digestível $^{6}$ & 2,45 & 2,00 & & 2,62 & \\
\hline E. Metabolizável ${ }^{6}$ & 2,01 & 1,64 & & 2,30 & $2,42^{7}$ \\
\hline Aminoac.Essenciais ${ }^{8}$ & & 53,3 & & & $49,3^{9}$ \\
\hline
\end{tabular}

${ }^{1}$ Ladeira et al. 2001: feno com mais de 50\% das plantas apresentando inflorescência

${ }^{2}$ Valadares Filho, 1981: feno confeccionado idade da planta de 112 dias.

${ }^{3}$ Borges 1988: feno confeccionado idade da planta de 112 dias.

${ }^{4}$ Foster et al. 1991: feno com $10 \%$ das plantas apresentando inflorescência.

${ }^{5}$ Dados expressos em matéria seca.

${ }^{6} \mathrm{Mcal} / \mathrm{kgMS}$.

${ }^{7}$ NRC (1996) alfafa em estádio vegetativo

${ }^{8} \mathrm{~g} / 100 \mathrm{~g}$ de aminoácidos

${ }^{9}$ Elizalde et al. 1999

Fonte: adaptado de Ladeira et al. 2002.

A distribuição modal de chuvas, com um período definido de déficit hídrico, e a baixa fertilidade natural dos solos, refletem-se na quantidade e qualidade da forragem produzida, e são responsáveis, em grande parte, pelos baixos índices zootécnicos do rebanho. O desempenho animal em pastagens tropicais tem demonstrado que, em parte, as deficiências apresentadas pelas gramíneas forrageiras tropicais, que comprometem o ganho por animal, são compensadas pela maior produção de massa de forragem, o que leva à maior capacidade de suporte e, conseqüentemente, aumento na produção por área.

Neste contexto, as leguminosas forrageiras tropicais têm importante papel a desempenhar. A formação de pastagens consorciadas ou como bancos de proteína foram as principais formas de utilização no
Brasil, América Latina, Austrália e Ásia. Inúmeros trabalhos indicam aumentos no ganho ou manutenção do peso de animais durante o período da seca, como resultado da melhor qualidade da leguminosa em associação com gramíneas (Tabela 4). Extensas revisões no Brasil sobre leguminosas subsidiam a importância e o potencial de adoção das pastagens consorciadas com leguminosas (Andrade \& Karia, 2000; Barcellos et al, 2001; Pereira, 2002).

Recentemente, em Nova Odessa-SP, durante o II Encontro Técnico sobre Leguminosas Forrageirasdesafios e perspectivas (Paulino, et al., 2008), o tema leguminosas forrageiras foi discutido e trouxe a possibilidade de convergência de diferentes instituições na busca de ampliar e aprofundar os estudos com leguminosas forrageiras. 
Tabela 2. Produtividade de alguns cultivares de leguminosas forrageiras. Registro mais freqüente e amplitude de valores conforme o ambiente e o manejo no Bioma Cerrado.

\begin{tabular}{|c|c|c|c|c|}
\hline \multirow[t]{2}{*}{ Cultivar } & Valor mais freqüente & $\begin{array}{l}\text { Amplitude de } \\
\text { valores }\end{array}$ & \multirow{2}{*}{$\begin{array}{c}\text { Incremento na } \\
\text { produtividade animal * } \\
\%\end{array}$} & \multirow[t]{2}{*}{ Principais diferenciais * } \\
\hline & \multicolumn{2}{|c|}{ Massa seca (t/ha.ano) } & & \\
\hline $\begin{array}{c}\text { Stylosanthes } \\
\text { macrocephala cv. Pioneiro }\end{array}$ & 3 & $2-6$ & 20 & Valor alimentício; Taxa de lotação \\
\hline $\begin{array}{l}\text { S.guianensis } \\
\text { cv. Bandeirante }\end{array}$ & 4 & $2-8$ & 30 & Valor alimentício; Taxa de lotação \\
\hline $\begin{array}{l}\text { S.guianensis } \\
\text { cv. Mineirão }\end{array}$ & 6 & $4-13$ & $30-50$ & $\begin{array}{c}\text { Valor alimentício; Taxa de lotação; Estresse } \\
\text { biótico; Estacionalidade da produção }\end{array}$ \\
\hline $\begin{array}{c}\text { S.capitata } \\
+ \text { S.macrocephala } \\
\text { cv. Campo Grande }\end{array}$ & 6 & $3-10$ & $10-30$ & Valor alimentício; Taxa de lotação \\
\hline $\begin{array}{l}\text { S.guianensis } \\
\text { cv. Bela }\end{array}$ & 8 & $3-10$ & 30 & Valor alimentício; Taxa de lotação \\
\hline $\begin{array}{c}\text { Arachis pintoi } \\
\text { BRA-040550** }\end{array}$ & 8 & $6-12$ & $20-40$ & Valor alimentício; Taxa de lotação \\
\hline
\end{tabular}

* Em relação ao cenário ou cultivar de referência; ** materiais não nominados para liberação comercial ou recomendação.

Estudos desenvolvidos no norte da Austrália, país com regiões de clima tropical e reconhecidamente adepto de leguminosas na alimentação de ruminantes, reportam resultados significativos quanto ao desempenho animal (Tabela 3). Uma grande proporção das pastagens consorciada (60\%) gerou ganhos em peso entre 400 e 800 g/animal/dia. Esta resposta, quando aplicados à situação brasileira, possibilitaria a terminação de animais em regime exclusivo de pasto com idade inferior a 36 meses. Para a recria de fêmeas, tanto de gado de corte como leiteiro, seria possível a entrada dos animais em reprodução com idade entre 18 e 20 meses. As maiores taxas de ganho, obtidas com pastagens puras, refletem o uso de fertilizantes nitrogenados. Cabe ainda ressaltar que grande parte das leguminosas implantada naquelas condições apresenta adaptação ao solo e clima do Brasil sendo, muitas delas, originárias do nosso país, como o caso dos estilosantes.

Tabela 3. Distribuição de freqüência (\%) de ganho de peso em pastagens de gramíneas puras e consorciadas no norte da Austrália

\begin{tabular}{ccccccc}
\hline Forrageiras & \multicolumn{6}{c}{ Taxa de ganho (kg/dia) } \\
\cline { 2 - 7 } & $<0,2$ & $0,2-0,4$ & $0,4-0,6$ & $0,6-0,8$ & $0,8-1,0$ & $>1,0$ \\
\hline $\begin{array}{c}\text { Gramínea } \\
(\mathrm{G})\end{array}$ & 17 & 28 & 17 & 11 & 11 & 16 \\
$\mathrm{G}+$ & 8 & 15 & 30 & 30 & 9 & 8 \\
leguminosa & & & & & & \\
\hline
\end{tabular}

Fonte: Adaptado de Winter et al. (1991)
No Brasil, Rocha et al. (1983) ao avaliarem 24 artigos com experimentos de longa duração em vários locais e diferentes sistemas de pastejo, combinações de gramíneas e de leguminosas, observaram que o ganho de peso vivo de bovinos foi, em média, de 329 $\mathrm{kg} / \mathrm{ha} / \mathrm{ano}$ (96 a $580 \mathrm{~kg} / \mathrm{ha}$ ) nos pastos consorciados e de $456 \mathrm{~kg} / \mathrm{ha} / \mathrm{ano}$ (350 a $592 \mathrm{~kg} / \mathrm{ha}$ ) em pastos adubados com nitrogênio (44 a 200 kg/ha N). Coates (1995) compilou resultados da produção animal em pastos consorciados com leguminosas herbáceas em vários locais e condições. O desempenho animal variou de 137 a 229 g/dia e a produtividade de 80 a 643 kg/ha. Pereira (2002) apresentou registros de 11 experimentos conduzidos no Brasil em que pastos consorciados foram confrontados com pastos sem leguminosas. Em média, os pastos consorciados proporcionaram 437 g/animal/dia (variando de 230-610g/dia) e os pastos exclusivos 333 g/dia (variação de 117-574 g/dia). Todos esses resultados foram obtidos em períodos de 1 a 6 anos e são apenas indicativos, pois o confronto dos resultados é dificultado, uma vez que encerram diferenças quanto ao tipo de solo, fertilidade, estação de pastejo, manejo, lotação, oferta de forragem, cultivar de gramínea e leguminosa, categoria animal, adubações etc. As taxas de lotação foram bastante variáveis, desde 0,5 cabeça/ha até 2,4 UA/ha (UA=unidade animal $=450$ $\mathrm{kg}$ de peso vivo). Em geral, os trabalhos recentes em sistemas extensivos nos locais com estação seca bem definida não têm proporcionado taxas de lotação acima de $1,5 \mathrm{UA} / \mathrm{ha} / \mathrm{ano}$. 
Analisando um conjunto de resultados de desempenho animal em pastagens puras e consorciadas Lascano e Avila (1991) afirmam que as leguminosas selecionadas para solos ácidos, como os do Cerrado brasileiro, em consórcio com gramíneas, contribuem para aumentar a produção de $20 \%$ a $30 \%$ de leite em vacas alimentadas em regime de pastejo. Por meio de simulação e conversão da energia para ganho de peso em produção de leite, no conjunto de resultados apresentados no corpo deste trabalho, verificou-se que a presença da leguminosa na pastagem consorciada incrementaria a média de produção em 2 litros de leite/vaca/dia, considerando uma forragem de com $60 \%$ de NDT. Para sistemas de produção em regime de pastagem e com vacas lactantes produzindo entre 10 e 12 litros diários o incremento na produção seria de cerca de 15 a $20 \%$. Os valores obtidos são significativos e podem promover grande impacto na produção de leite.

\section{Alternativas de usos de leguminosas forrageiras em pastagens}

Resultados obtidos, principalmente no Cerrado, demonstram o impacto do uso de leguminosas nas pastagens. A adoção de consórcio entre gramíneas e leguminosas tem possibilitado a superação de problemas como a qualidade da forragem, especialmente na estação de seca. A Figura 1 demonstra o desempenho animal em pastagens de Andropogon gayanus consorciada com Stylosanthes guianensis cv. Mineirão. Uma das limitações do Andropogon é sua baixa qualidade na estação seca que pode ser superada com a associação gramínea e leguminosa.

$\mathrm{O}$ uso de leguminosas no processo de recuperação de pastagens degradadas tem ganhado destacada importância. A possibilidade de melhoria na dieta animal e a reciclagem de nutrientes resultam em maior produção por animal e por área. Trabalhos conduzidos em fazendas, na região de Uberlândia, em solos arenosos e argilosos, compararam a recuperação direta da pastagem com e sem leguminosa. A inclusão do estilosantes Mineirão nas pastagens degradadas de $B$. decumbens e Brachiaria ruziziensis foi responsável por aumento no ganho diário de peso de novilhas nelore e na produtividade da pastagem (Tabela 4). Considerando um incremento de 4,5 @ por hectare por ano, a inclusão do Mineirão foi economicamente rentável, pois a diferença de custo entre os dois sistemas (com e sem leguminosa) foi apenas o valor de 0,8 quilos de sementes de Mineirão por hectare (Vilela et al., dados não publicados).

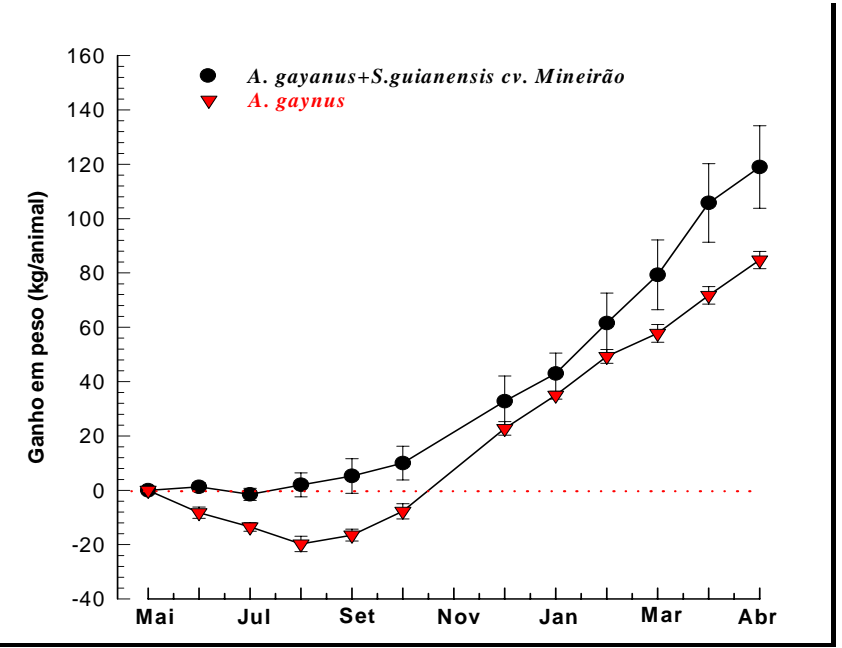

Figura. 1. Efeito de leguminosas no ganho de peso de novilhas azebuadas durante os períodos de seca e chuvas (1993/94). Fonte: Vilela et al. (2001).

Tabela 4. Efeito de pastagens de Brachiaria spp recuperadas pela introdução de Stylosanthes guianensis cv. Mineirão, em dois solos de Uberlândia (MG), no ganho de peso de novilhas nelore.

\begin{tabular}{|c|c|c|c|c|c|c|}
\hline Local/Épocas & $\begin{array}{c}\mathrm{g} / \mathrm{dia} / \\
\text { an }\end{array}$ & kg/ha & $\begin{array}{c}\text { Lotação } \\
\text { (UA/ha) } \\
1\end{array}$ & $\begin{array}{c}\mathrm{g} / \mathrm{dia} / \\
\text { an }\end{array}$ & $\mathrm{kg} / \mathrm{ha}$ & $\begin{array}{c}\text { Lotaçã } \\
\text { o } \\
(\mathrm{UA} / \mathrm{h} \\
\mathrm{a})^{1} \\
\end{array}$ \\
\hline $\begin{array}{c}\text { Fazenda } \\
\text { Cachoeira }^{2}\end{array}$ & \multicolumn{3}{|c|}{ B ruziziensis + Mineirão } & \multicolumn{3}{|c|}{ B. ruziziensis pura } \\
\hline Anual & \multicolumn{3}{|c|}{303} & \multicolumn{3}{|c|}{190} \\
\hline Chuvas & 450 & & 1,42 & 406 & & 1,27 \\
\hline Seca & -12 & & 0,86 & -72 & & 1,18 \\
\hline $\begin{array}{l}\text { Fazenda } \\
\text { Santa Inês }\end{array}$ & \multicolumn{3}{|c|}{$\begin{array}{l}\text { B. decumbens + } \\
\text { Mineirão }\end{array}$} & \multicolumn{3}{|c|}{ B. decumbens pura } \\
\hline Anual & \multicolumn{3}{|c|}{460} & \multicolumn{3}{|c|}{301} \\
\hline Chuvas & 622 & & 1,51 & 511 & & 1,17 \\
\hline Seca & 205 & & 0,80 & 131 & & 0,80 \\
\hline
\end{tabular}

1/ UA $=450 \mathrm{~kg}$ de peso vivo. 2/ Latossolo intermediário Areia Quartzosa franco arenoso. Período de avaliação de 779 dias. 3/ Latossolo Vermelho Escuro argiloso. Período de avaliação de 806 dias.

Fonte: Vilela et al., 1999. 
No Mato Grosso do Sul, em solos arenosos, trabalhos de recuperação de pastagens degradadas de B. decumbens com o uso de estilosantes Campo Grande forneceram resultados de grande expressão. Naquelas condições, pastagens recuperadas com estilosantes Campo Grande permitiram que os animais ganhassem aproximadamente três arrobas a mais por ano que os animais nos pastos recuperados sem o uso da leguminosa (Tabela 5) (Valle et al., 2001).

Tabela 5. Efeito da inclusão do estilosantes Campo Grande no ganho de peso na recria de bezerros nelore em pastagens recuperadas de $B$. decumbens.

\begin{tabular}{|c|c|c|c|c|c|c|}
\hline \multirow[t]{2}{*}{ Período } & \multicolumn{2}{|c|}{ 0,6 UA/ha } & \multicolumn{2}{|c|}{$1,0 \mathrm{UA} / \mathrm{ha}$} & \multicolumn{2}{|c|}{ 1,4 UA/ha } \\
\hline & $\mathrm{B}+\mathrm{CG}$ & $\mathrm{BP}$ & $\mathrm{B}+\mathrm{CG}$ & $\mathrm{BP}$ & $\mathrm{B}+\mathrm{CG}$ & $\mathrm{BP}$ \\
\hline $97 / 98$ & 138 & 139 & 264 & 220 & 330 & 309 \\
\hline 98/99 & 225 & 187 & 380 & 308 & 470 & 367 \\
\hline $99 / 00$ & 234 & 204 & 302 & 259 & 472 & 330 \\
\hline TOTAL (kg/ha) & 597 & 530 & 946 & 787 & 1.272 & 1.006 \\
\hline Arroba/ha & 21,2 & 18,7 & 34,4 & 27,8 & 45,0 & 35,5 \\
\hline Diferença - Arroba/ha & $+2,4$ & & $+6,6$ & & $+9,5$ & \\
\hline
\end{tabular}

Fonte: (Embrapa Gado de Corte, 2000; Valle, et al., 2001. UA = $450 \mathrm{~kg}$ de peso vivo

Avaliando o desempenho de animais Nelore, na fase de recria e terminação em pastagens recuperadas, foram observados ganhos altamente satisfatórios no consórcio de Brachiaria decumbens, consorciada com S. guianensis cv. Mineirão e B. brizantha cv. Marandu, complementado com banco de proteína dessa leguminosa (Barcellos e Vilela, 2001). Foi quantificado o desempenho em ganho de peso de novilhos dos 14 meses de idade até o abate (29 meses). A lotação média de ambas as pastagens foi de 1,47 UA/ha durante o período de avaliação (1UA=450 kg de peso vivo). $\mathrm{Na}$ estação seca houve a elevação na lotação devido a oferta de forragem existente no banco de proteína, acumulada durante a estação de crescimento. Os animais atingiram o peso médio de $500 \mathrm{~kg}$ aos 29 meses de idade, suplementados com mistura mineral nas chuvas e mistura múltipla na seca.

A informação contida na Tabela 6 refere-se a trabalho desenvolvido na Embrapa Gado de Corte e colabora para demonstrar as vantagens da associação entre gramíneas e leguminosas após três anos de pastejo. Tanto os ganhos por animal como a produção por área e as respectivas capacidades de suporte comprovam a aplicabilidade dessa tecnologia. O desempenho inferior da pastagem consorciada com a cv. Marandu foi atribuída a menor participação da leguminosa. Essa gramínea, em função de sua agressividade, tem apresentado limitações para obtenção de consórcios mais estáveis.
Tabela 6. Produção por animal e por área, em pastagem consorciada de Brachiaria com Mineirão no terceiro ano de pastejo.

\begin{tabular}{|c|c|c|c|c|}
\hline \multirow{2}{*}{$\begin{array}{c}\text { Época do } \\
\text { ano }\end{array}$} & \multicolumn{2}{|c|}{ Ganho de peso vivo } & \multicolumn{2}{|c|}{ Taxa de lotação } \\
\hline & g/animal/dia & $\mathrm{Kg} / \mathrm{ha}$ & animal/ha & UA/ha \\
\hline \multicolumn{5}{|c|}{ B. decumbens+Mineirão } \\
\hline Chuvas & 515 & 364 & 3,7 & 1,9 \\
\hline Seca & 252 & 100 & 3,1 & 1,1 \\
\hline Anual & 409 & 464 & 3,6 & 1,6 \\
\hline \multicolumn{5}{|c|}{ B. brizantha+Mineirão } \\
\hline Chuvas & 466 & 298 & 3,4 & 1,5 \\
\hline Seca & 136 & 54 & 3,1 & 1,0 \\
\hline Anual & 333 & 352 & 3,3 & 1,3 \\
\hline
\end{tabular}

Fonte: Almeida (2001).

Na recria de bovinos, em áreas úmidas na Embrapa Cerrados- Planaltina (DF), pastagens de A. pintoi BRA-031143 consorciado com Paspalum atratum cv. Pojuca geraram produções acima de 600 $\mathrm{kg} / \mathrm{ha} / \mathrm{ano}$ de peso vivo (Barcellos et al., 1996). Os resultados evidenciaram a qualidade e o potencial do consórcio de Arachis na recria de bovinos. As produções obtidas são compatíveis com as alcançadas em sistemas de produção baseada em pastagens fertilizada com nitrogênio (Tabela 7).

A utilização de A. pintoi em sistemas de produção de leite tem gerado resultados expressivos (Tabela 8). Em pastagens de capim Estrela puro e consorciado foram obtidos aumentos na produção diária de leite entre 1,1 e 1,4 kg de leite/vaca. A produção por área foi 
aumentada em 14,3\% e 13,6\% em dois períodos de avaliação (Gonzales et al. 1996). Os autores relatam que as produções poderiam ser ainda maiores se fosse adotada a suplementação dos animais com uma fonte de energia para aumentar a eficiência do uso do excedente de nitrogênio ruminal. Esta observação tem grande relevância no manejo alimentar de animais consumindo A. pintoi, devido à alta taxa de degradação protéica dessa forragem, exigindo o uso de energia prontamente disponível para maximizar seu potencial nutritivo (Ladeira et al. 2002)

Tabela 7. Desempenho de bovinos em pastagem de Arachis pintoi BRA-031143 consorciada com Paspalum atratum BRA-009610 em ambiente de várzea, em Planaltina, DF.

\begin{tabular}{ccccc}
\hline & \multicolumn{5}{c}{ CICLOS DE PASTEJO } \\
\cline { 2 - 5 } PARAMETROS & $1992 / 93$ & $1993 / 94$ & $1994 / 95^{1}$ & $1995 / 96^{2}$ \\
\hline $\begin{array}{c}\text { Taxa de lotação } \\
\text { (UA/ha) }\end{array}$ & 2,90 & 1,95 & 2,92 & 3,62 \\
\hline $\begin{array}{c}\text { GMD }^{4} \text { período da } \\
\text { seca (g/an/dia) }\end{array}$ & $203 \pm 16$ & $99 \pm 36$ & - & - \\
\hline Dias de pastejo & 168 & 140 & - & - \\
\hline $\begin{array}{c}\text { GMD } \\
\text { chuva (gríodo da } / \text { dia) }\end{array}$ & $387 \pm 17$ & $578 \pm 68$ & $697 \pm 35$ & $687 \pm 123$ \\
\hline $\begin{array}{c}\text { Dias de pastejo } \\
\text { cyyyy}\end{array}$ & 168 & 158 & 238 & 129 \\
\hline $\begin{array}{c}\text { Produção (kg } \\
\text { PV/ha/ano) }\end{array}$ & 574 & 793 & 545 & 610 \\
\hline
\end{tabular}

1.Avaliação entre out./94 e maio/95. 2. Avaliação entre nov./95 e maio/96. 3. UA $=450 \mathrm{~kg}$ de peso vivo. $4 . \mathrm{GMD}=$ Ganho médio diário. 5. $\mathrm{PV}=$ peso vivo.

Fonte: Barcellos et al., 1996.

Tabela 8. Produção de leite em pastagens de capim Estrela Africana (Cynodon nlemfuensis) em monocultivo e consorciado com Arachis pintoi.

\begin{tabular}{cccc}
\hline Produção & $\begin{array}{c}\text { Capim } \\
\text { Estrela }\end{array}$ & $\begin{array}{c}\text { Estrela + A. } \\
\text { pintoi }\end{array}$ & Incremento (\%) \\
\cline { 2 - 4 } & \multicolumn{3}{c}{$\mathbf{1 9 9 0}$} \\
\hline $\mathrm{kg} / \mathrm{vaca} /$ dia & $7,7 \mathrm{~b}$ & $8,8 \mathrm{a}$ \\
\hline $\mathrm{kg} / \mathrm{ha} / \mathrm{dia} *$ & 22,3 & 25,5 & 14,3 \\
\hline \multicolumn{4}{c}{$\mathbf{1 9 9 1 - \mathbf { 1 9 9 2 }}$} \\
\hline $\mathrm{kg} / \mathrm{vaca} /$ dia & $9,5 \mathrm{~b}$ & $10,9 \mathrm{a}$ \\
\hline $\mathrm{kg} / \mathrm{ha} / \mathrm{dia}$ & 22,8 & 25,9 & 13,6 \\
\hline
\end{tabular}

* Lotação de 2,9 e 2,4 U.A. em 1990 e 1991/1992, respectivamente.

Fonte: Adapatado de Gonzalez et al. (1996).
Trabalhos desenvolvidos em regiões de clima tropical úmido, em pastagens de grama Estrela e $B$. humidicola associadas, que receberam $250 \mathrm{~kg} / \mathrm{ha} / \mathrm{ano}$ de nitrogênio, e suplementada com banco de proteína de $A$. pintoi, permite verificar a qualidade dessa forrageira. As novilhas em recria tiveram acesso por 5 horas ao banco de proteína e receberam diferentes quantidades de suplemento concentrado. Os ganhos obtidos compensaram a diminuição na quantidade de concentrado oferecido, e quando estas tiveram acesso ao banco de leguminosas, ganharam significativamente mais peso do que o grupo mantido apenas com concentrado (Tabela 9). Este sistema possibilitou maior economia e eficiência na recria. Relatos de trabalhos indicam que a inclusão de $A$. pintoi em pastagens puras de gramínea possibilitou incrementos de 17 a $20 \%$ na produção de leite.

A utilização do amendoim forrageiro como banco de proteína em um sistema de produção de leite, em uma pequena propriedade familiar do Acre, resultou em aumento na produção de leite de 3,6 para 5,2 litros/vaca/dia (Valentim, et al. 2001). Neste sistema, as vacas pastavam no banco de proteínas por 2 a 5 horas/dia, após a ordenha.

Tabela 9. Ganho de peso de novilhas Jersey com e sem acesso ao banco de proteína de A. pintoi. Ochomogo, Costa Rica.

\begin{tabular}{ccc}
\hline Ensaios & Carga (UA/ha) & $\begin{array}{c}\text { Ganho } \\
\text { (g/animal/dia) }\end{array}$ \\
\hline $\begin{array}{c}\text { Com acesso ao A. pintoi +1,5 } \\
\mathrm{kg} / \text { dia de concentrado }\end{array}$ & 3,3 & $595 \mathrm{a}$ \\
\hline $\begin{array}{c}\text { Sem acesso ao A. pintoi +2 } \\
\mathrm{kg} / \text { dia de concentrado }\end{array}$ & 3,3 & $554 \mathrm{~b}$ \\
\hline $\begin{array}{c}\text { Com acesso ao A. pintoi +1 } \\
\mathrm{kg} / \text { dia de concentrado }\end{array}$ & 4,2 & $537 \mathrm{c}$ \\
\hline $\begin{array}{c}\text { Sem acesso ao A. pintoi +1 } \\
\mathrm{kg} / \text { dia de concentrado }\end{array}$ & 4,2 & $444 \mathrm{~d}$ \\
\hline
\end{tabular}

Fonte: Quan et al. (1996).

Estudos desenvolvidos no estado de São Paulo com pastagens de $B$. brizantha fertilizadas com nitrogênio, em relação a pastagens da mesma espécie associada a banco de proteína de leucena (BPL) e animais suplementados todo ano e somente na seca, indicaram claramente o potencial de produção desta leguminosa (Tabela 10). Durante a estação de chuvas e de seca o ganho médio diário e a produção/ha das pastagens com BPL superaram os valores obtidos na 
área com dose de $100 \mathrm{~kg} / \mathrm{ha}$ de nitrogênio. A produção/ha total, somando a estação seca e chuvosa, foi superior aos demais tratamentos apenas quando a suplementação foi adotada durante todo ano (Lourenço e Leme, 1999)

Tabela 10. Efeito do banco de proteína de leucena e de suplementação alimentar no ganho de peso de novilhos Nelore em pastagens de $B$. brizantha cv. Marandu. Período de avaliação: Junho/97 a Março/98 (277 dias)

\begin{tabular}{ccccc}
\hline Sistema & \multicolumn{2}{c}{ Seca } & \multicolumn{2}{c}{ Chuvas } \\
\cline { 2 - 5 } & $\mathrm{kg} / \mathrm{dia}$ & $\mathrm{kg} / \mathrm{ha}$ & $\mathrm{kg} /$ dia & $\mathrm{kg} / \mathrm{ha}$ \\
\hline $\begin{array}{c}\text { B. brizantha }(\mathrm{Bb})+100 \\
\text { kg/ha/ano de N }\end{array}$ & 0,498 & 77 & 0,345 & 120 \\
\hline $\mathrm{Bb}+\mathrm{BP}$ de Leucena & 0,562 & 87 & 0,472 & 166 \\
\hline $\begin{array}{c}\mathrm{Bb}+100 \mathrm{~kg} / \mathrm{ha} / \mathrm{ano} \text { de } \\
\mathrm{N}+\text { supl. seca }\end{array}$ & 0,700 & 109 & 0,352 & 122 \\
\hline $\begin{array}{c}\mathrm{Bb}+100 \mathrm{~kg} / \mathrm{ha} / \mathrm{ano} \text { de } \\
\text { N+supl. ano }\end{array}$ & 0,719 & 112 & 0,592 & 207 \\
\hline
\end{tabular}

Suplemento das secas: $67,5 \%$ NDT e $46,4 \%$ PB; consumo médio de $756 \mathrm{~g} / \mathrm{animal} / \mathrm{dia}$

Suplemento das secas: $68 \%$ NDT e $37 \%$ PB; consumo médio de $944 \mathrm{~g} / \mathrm{animal} / \mathrm{dia}$

Fonte: Adaptado de Lourenço e Leme, 1999.

Manella et al. (2002) avaliaram o desempenho de bovinos Nelore em pastagens de $B$. brizantha, suplementada durante todo ano, durante a seca, acesso a banco de proteína $L$. leucocephala e pasto exclusivo. Verificaram ganhos médios diários, durante um período de 314 dias, de 649, 562, 534 e 447 g.animal ${ }^{-1}$ respectivamente. Os valores são equivalentes e guardam a mesma relação com os obtidos por Lourenço \& Leme (1999).Os autores ainda constataram que, durante as águas, os ganhos obtidos em pastagens com Leucaena (741 g.dia ${ }^{-1}$ ) não diferiram dos ganhos obtidos nos animais do tratamento suplementados durante todo o ano (782 g.dia $\left.{ }^{-1}\right)$. Os ganhos por animal, obtidos nos tratamentos com pastagem sem suplementação (645 g.dia $\left.{ }^{-1}\right)$ e suplementados na seca (584 g.dia $\left.{ }^{-1}\right)$, foram inferiores aos demais. A produção por hectare teve o mesmo comportamento estatístico durante a estação da águas. A produtividade animal obtida durante todo o período de avaliação foi de 598, 714, 739, e 835 kg.ha ${ }^{-1}$ para os tratamentos com pasto exclusivo, com acesso a Leucaena, suplementada na seca e todo o ano. São ainda relatadas necessidades de estudos para melhor aproveitar os ganhos compensatórios obtidos nas áreas com Leucaena, por meio de ajuste da suplementação protéica e energética. Na complementação deste estudo, foi sugerida a necessidade de suplementação protéica para B.brizantha durante a estação chuvosa (Manella et al., 2003), existindo a possibilidade de integração das estratégias de suplementação avaliadas para maximizar a produção por animal e por hectare.

Barcellos (2006) conduziu estudos de desempenho animal, na recria de fêmeas nelore, em pastos consorciados de Leucaena híbrida 11x25 com Brachiaria brizantha cv. Marandu, na região do Cerrado. A implantação da Leucaena ocorreu em associação com a cultura da soja. Utiliza-se a semeadura da Leucaena em faixas de dois metros, contendo duas linhas espaçadas de um metro, ocupando $25 \%$ da área total. Depois da colheita da soja, promoveu-se a semeadura com a cv. Marandu. Na fase de utilização da pastagem, adotou-se sistema de pastejo com lotação intermitente (12 dias de ocupação e 36 dias de descanso). Os pastos exclusivos proporcionaram lotações de 3,11 a 4,35 e de 3,11 a 4,58 novilhas.ha $^{-1}$ nos pastos consorciados, durante dois anos de avaliação (média de 218 dias.ano $^{-1}$ ). O ganho médio diário variou de 438 a 539 g.animal $^{-1}$.dia ${ }^{-1}$, nos pastos exclusivos, e de 530 a 694 g.animal ${ }^{-1}$.dia ${ }^{-1}$ nos pastos consorciados. Os incrementos no ganho médio diário, na produção por animal e na produtividade, quando comparado com o desempenho animal em pasto exclusivo de gramínea, foram superiores. O acréscimo no ganho médio diário de peso foi de $25 \%$ e a produtividade foi elevada em $33 \%$ (412,5 kg.ha $\left.{ }^{-1}\right)$, em relação à pastagem pura (309 $\mathrm{kg} \mathrm{ha}^{-1}$ ), no mesmo nível de fertilização nitrogenada (60 kg de N.ha ${ }^{-1} \cdot$ ano $^{-1}$ ). O consumo adicional de proteína por animal, proporcionado pela leguminosa, variou de 402 a 616 g.animal $^{-1} \cdot$ dia $^{-1}$. Os incrementos obtidos no desempenho animal (g.dia) e na produtividade na pastagem consorciada resultaram em maior eficiência em termos de $\mathrm{kg}$ de peso corporal (PC). $\mathrm{kg}^{-1}$ de $\mathrm{N}$ aplicado. O valor obtido, na média de dois anos de avaliação, de 3,33 kg PC.kg ${ }^{-1}$ de N aplicado permitiu retorno bioeconômico da fertilização nitrogenada em pastagens consorciadas com Leucaena,, não sendo observado o mesmo comportamento para as pastos exclusivos, com valor, médio, de 1,63 kgPC. $\mathrm{kg}^{-1}$ de $\mathrm{N}$ aplicado.

\section{Considerações finais}

A intensificação de sistemas de produção em regime de pastagens deverá ser pautada pelo uso 
eficiente dos recursos naturais e financeiros, buscando minimizar riscos de perdas econômicas e compromisso ambiental. A utilização de leguminosas vem ao encontro dessas premissas que levam a sustentabilidade. A capacidade de tamponamento exercida pela leguminosa quanto à manutenção de um valor nutritivo mais elevado na forragem e na dieta, assegurando maior ganho por animal, são aspectos relevantes do processo de intensificação da produção animal.

Sem dúvida, o manejo de consórcios é mais complexo que pastagens puras, pois inclui os efeitos de competição entre espécies na comunidade, a seletividade animal sobre os componentes, dentre outras pressões bióticas e abióticas determinando a persistência e contribuição da leguminosa para os sitema solo-planta-animal. Um grande esforço foi despendido para compreensão dos componentes de manejo em gramíneas, especialmente dos gêneros Panicum, Brachiaria e Cynodon. O sucesso dos resultados e as competências técnicas envolvidas nas instituições de ensino e pesquisa serão essenciais para alcançar semelhante avanço no conhecimento sobre as leguminosas em ecossistemas de pastagens.

Apesar das relevantes possibilidades de contribuição para produção de bovinos a pasto e dos muitos esforços já envidados por diferentes instituições de ensino e pesquisa, o uso de leguminosas em pastagens no Brasil ainda é muito limitado, seja porque o portfólio de cultivares é pequeno, o preço da semente ou do material vegetativo é elevado, a persistência sob pastejo é limitada, o estabelecimento é lento ou, principalmente, porque o real papel que elas podem desempenhar nos sistemas de produção de bovinos é desconhecido. E se conhecidos, não são suficientemente fortes para sensibilizar na adoção. Para a reversão desse quadro, pastagens consorciadas devem gerar a percepção de tecnologia de baixo risco e de baixo custo. Para tanto, a adoção deve ser fundamentada no conhecimento das potencialidades e limitações dos cultivares e na deteç̧ão das melhores oportunidades de inclusão nos sistemas de produção de bovinos, visando ampliar o uso dessa opção tecnológica.

\section{Referência bibliográficas}

ALMEIDA, R.G. Avaliação de pastagens de braquiárias consorciadas com estilosantes, sob três taxas de lotação, no Cerrado. Viçosa: UFV, 2001. 82 p. (Tese Doutorado).
ANDRADE, R. P. de ; KARIA, C. T. . Uso de Stylosanthes em pastagens no Brasil. In: SIMPÓSIO DE FORRAGICULTURA E PASTAGENS: TEMAS EM EVIDÊNCIA, 2000, Lavras. Anais. Lavras : Universidade Federal de Lavras, p.273-310, 2000.

BARCELLOS, A. de O. Avaliação agronômica de híbrido interespecífico de Leucaena e sua qualidade em associação com Brachiaria brizantha cv. Marandu. 2006. 217 f. Tese (Doutorado em Zootecnia) - Faculdade de Ciências Agrárias e Veterinárias, Universidade Estadual Paulista, Jaboticabal, 2006.

BARCELLOS, A. O.; COSTA, N. de L.; PIZARRO, E.A. Avaliação sob pastejo em pequenas parcelas de Arachis pintoi consorciado com Paspalum atratum em solo de várzea. In: REUNIÃO DA SOCIEDADE BRASILEIRA DE ZOOTECNIA, 33. Fortaleza, 1996. Anais..... 1996. v.1. p.218-220.

BARCELLOS, A.O.; ANDRADE, R.P.; KARIA, C.T.; VILELA, L. Potencial e uso de leguminosas forrageiras dos gêneros Stylosanthes, Arachis e Leucaena. In: PEIXOTO, A.M.; PEDREIRA, C.G.S.; FARIA, V.P.(eds) SIMPÓSIO SOBRE MANEJO DA PASTAGEM, 17, 2001, Piracicaba. Anais... Piracicaba: FEALQ, 2001. p.365-426.

BARCELLOS, A. de O.; VILELA, L. Restabelecimento da capacidade produtiva de pastagens por meio de introdução de Stylosanthes guianensis cv. Mineirao. Planaltina: Embrapa Cerrados, 2001. 5 p. (Embrapa Cerrados. Comunicado Técnico, 65).

Barioni, L. G., Martha Júnior, G. B., Ramos, A. K. B., Veloso, R. F. Rodrigues, D. C., Vilela, L. 2003. Planejamento e gestão do uso de recursos forrageiros na produção de bovinos em pastejo. Pages 105-153 in Simpósio Sobre o Manejo da Pastagem. FEALQ, Piracicaba, São Paulo.

Barros, A. L. M., Zimmermann, A., Souza, C. R. S., Ichihara, S.M. 2003. Considerações acerca da avaliação de projetos de investimentos. Pages 301-326 in Simpósio Sobre o Manejo da Pastagem. FEALQ, Piracicaba, São Paulo.

BLUM, J.W.; BRUCKMAIER, R.M.; JANS, F. Rumenprotected methionine fed to dairy cows: bioavailability and effects on plasma amino acid pattern and plasma metabolite and insulin concentrations. Journal of Dairy Science, v.82, n.9, p.1991-1998, 1999.

CANTARUTTI, R.B.; BODDEY, R.M. Transferência de nitrogênio das leguminosas para as gramíneas. In: SIMPÓSIO INTERNACIONAL SOBRE PRODUÇÃO ANIMAL EM PASTEJO. 1997, Viçosa. Anais... Viçosa: UFV, 1997, p. 431-445.

CERRI, C.E.P; EASTER, M.; PAUSTIAN, K. et al,. Simulating SOC changes in 11 land use change from Brazilian Amazon whith RothC and Century models. Agriculture, Ecosystems and Environment, v. 122, p. 46-57, 2007.

COATES, D.B. Tropical legumes for large ruminants. In: D’MELLO, J.P.F.; DEVENDRA, C. (eds). Tropical legumes in animal nutrition. CAB International, Wallingford. 1995. p.191-230.

EMBRAPA GADO DE CORTE. Estilosantes Campo Grande: estabelecimento, manejo e produção animal. Campo Grande: Embrapa Gado de Corte, 2000, 8p. (Embrapa Gado de Corte, Comunicado Técnico $\mathrm{N}^{\mathrm{o}}$ 61).

FORNARA, D.A; TILMAN, D. Plant functional composition influences rates of soil carbon and nitrogen accumulation. Journal of Ecology, v. 9, p314-322, 2008.

FISHER, M. J.; RAO, I.M.; THOMAS, R.J. Nutrient cycling in tropical pastures, with special reference the neotropical 
savannas. In: INTERNATIONAL GRASSLAND CONGRESS, 18, Winnipeg/ Saskatoo, 1997. Proceedings... Winnipeg/ Saskatoo: Association management centre, 1997. p.371-382.

GOMES S.T. Matrizes de restrições ao desenvolvimento do segmento da produção de leite na região Centro Oeste. In. BRESSAN, M., VLELA D. Restrições técnicas, econômicas e institucionais o desenvolvimento da cadeia produtiva de leite no Brasil. -Região Centro Oeste. Brasília: MCT/CNPq/PADCT, Juiz de Fora: Embrapa Gado de Leite. p.21-25. 1999.

GONZALES, M. S.; NEURKVAN, L. M.; ROMERO, F. et al. Producion de leche en pasturas de estrella africana (Cynodon nlemfluensis) solo y associado con Arachis pintoi o Desmodium ovalifolium. Pasturas tropicales, v. 18, n. 1, p. 2-12. 1996.

HuMPHREYS, L.R. Tropical pasture utilisation. Cambridge University Press, Cambridge. 1991. 206 p.

HuMPHREYS, L.R. Tropical forages : their hole in sustainable agriculture. Esses, UK: Longman Scientific \&Technical, 1994. 414p.

IBGE. 1997. Anuário Estatístico do Brasil - 1997. Rio de Janeiro, Brazil.

Ladeira, M. M.; Rodriguez, N. M.; Borges, I.; Gonçalves, L. C.; Saliba, E. O.S.; Brito, S. C.; Sá, L. A. P. Avaliação do Feno de Arachis pintoi Utilizando o Ensaio de Digestibilidade in Vivo . Revista Brasileira de Zootecnia, v.31, n.6, p.2350-2356, 2002.

LASCANO, C.E., AVILA, P. Potencial de producción de leche en pasturas solas y asociadas con leguminosas adaptadas a suelos ácidos. Pastura Tropical, 13:2-10, 1991.

LEDGARD, S.F., STEELE, K.W. Biological nitrogen fixation in mixed legume/grass pastures. Plant and Soil, v.141, n.1-2, p.137-154, 1992.

Lourenço, A. J.; LEME, P.R. Desempenho animal em pastagens de Brachiaria brizantha associado a banco de proteína ou suplementação alimentar. In: REUNIÃO ANUAL DA SOCIEDADE BRASILEIRA DE ZOOTECNIA, 36, Porto Alegre, 1999. Anais. Porto Alegre, SBZ, 1999. (CD ROOM)

MANELLA, M.Q; LOURENÇO, A.J.; LEME, P.R. Recria de bovinos Nelore em pastos de Brachiaraia brizantha com suplementação protéica e com a cesso a banco de proteína de Leucaena leucocephala. Característica de fermentação ruminal. Revista Brasileira de Zootecnia, Viçosa, v. 32 n 4, p. 1002-1012 , 2003.

MANELLA, M.Q; LOURENÇO, A.J.; LEME, P.R. Recria de bovinos Nelore em pastos de Brachiaraia brizantha com suplementação protéica e com a cesso a banco de proteína de Leucaena leucocephala. Desempenho animal. Revista Brasileira de Zootecnia, Viçosa, v. 31 n. 6, p. 2274-2282, 2002.

MARTHA Jr., G.B.; VILELA, L.; BARCELLOS, A.O.; BARIONI, L.G.; SOUSA, D.M.G. Pecuária de corte no Cerrado: uma visão conjuntural. In: MARTHA JR., G.B.; VILELA, L.; SOUSA, D.M.G. (Ed.) Uso Eficiente de Fertilizantes em Pastagens no Cerrado. Planaltina: Embrapa Cerrados, 2006a.

Martha Júnior, G.B.; Corsi, M.; Trivelin, P.C.O.; Vilela, L.; Pinto, T.L.F.; Teixeira, G.M.; Manzoni, C.S.; Barioni, L.G. 2004 b. Perda de amônia por volatilização em pastagem de capim Tanzânia adubada com uréia no verão. Revista Brasileira de Zootecnia, 33: 2240-2247.
MONTENEGRO, J.; ABARCA, S. Fijación de carbono, emisión de metano y óxido nitroso en sistemas de produción bovina en Costa Rica. En. Intensificación de la ganaderia en Centroamérica - benefícios economicos y ambientales. CATIE-FAO-SIDE. Editado por Nuetra Terra, 2000. 334p.

NORTON, B.W.; POPPI, D.P. Composition and nutritional attributes of pasture legumes. In: D’MELLO, J.P.F.; DEVENDRA, C. (eds). Tropical legumes in animal nutrition. CAB International, Wallingford. 1995. p.23-48.

PAULINO, V. P.; LUCENA, M.A.C.; GERDES, L.; COLOZZA, M.T; BRAGA, G.J. II Encontro Técnico sobre Leguminosas Forrageiras - desafios e perspectivas. Nova Odessa. Anais... (ed.). Instituto de Zooecnia, Nova Odessa, São Paulo. Abril de 2008. 168p. ( CD ROOM)

PEOPLES, M.B.; CRASWELL, E.T. Biological nitrogen fixation: investments, expectations and actual contributions to agriculture. Plant and Soil, v.141, n.1-2, p.13-40, 1992.

POSSENTI, R. Efeitos de dietas de Leucaena leucocephala com ou sem adição de Sacharomyces cerevisiae na digestão, fermentação, protozoários e produção de metano no rumem em bovinos. 98 f. Tese (Doutorado). Pirassununga, USP, 2006.

PEREIRA, J.M. Leguminosas forrageiras em sistemas de produção de ruminantes: Onde estamos ? Para onde vamos ? In: SIMPÓSIO SOBRE O MANEJO ESTRATÉGICO DA PASTAGEM , 2002, Viçosa. Anais... Viçosa: UFV, 2002, p. 109-147.

POPPI, D.P.; norton, b.w. Intake of tropical legumes. In: D’MELLO, J.P.F.; DEVENDRA, C. (eds). Tropical legumes in animal nutrition. CAB International, Wallingford. 1995. p.173-190.

QUAN, A. A.; ROJAS, B. A.; VILLALOBOS, L. Arachis pintoi CIAT 18744 como banco de proteína para el desarrollo de terneras de reemplazo. In: P. J. ARGEL; RAMIREZ, P. (eds.). Experiencias regionales com Arachis pintoi y planes futuros de investigación y promoción de la especie en México, Centroamérica y el caribe. Centro Internacional de Agricultura Tropical (CIAT), Cali, Colombia. 1996. p. 2634.

RAMOS, A. K. B.; KARIA, C. T.; ANDRADE, R. P. de; BARCELLOS, A. de O.; VILELA, L. Consorciação de gramíneas e leguminosas para a produção de bovinos. In: OLIVEIRA, R. L.; FRANCO, G. L. ; BARBOSA, M. A. A. de F.; BARBOSA, A. M. M. A. F. (Orgs.) Congresso Brasileiro de Zootecnia - ZOOTEC, 2004, Brasília. Anais. Brasília: ABZ, AZOO-DF, UPIS, 2004. p. CD-ROM

REZENDE, G.C. Ocupação agrícola, estrutura agrária, mercado de trabalho rural no Cerrado: o papel do preço da terra, dos recursos naturais e das políticas públicas. In HELFAND, S.M.; REZENDE, G.C. Região e espaço no desenvolvimento agrícola brasileiro. Rio de Janeiro:IPEA, 2003, cap. 4, p. 173-212.

ROCHA, G.L.; ALCÂNTARA, V.B.G.; ALCÂNTARA, P.B. Animal production from brazilian tropical pastures. In: INTERNATIONAL GRASSLAND CONGRESS, 14, Lexington/ Kentucky, 1981. Proceedings... Westview Press: Boulder, Colorado: Westview Press, 1983. p.771774.

SALTON, J; MIELNICZUK, J; BAYER, C; et al,. Agregação e estabilidade de agregados do solo em sistemas agropecuários em Mato Grosso do Sul. Revista Brasileira de Ciência do Solo, n. 32, p. 11-21, 2008.

SANO, E..E; ROSA, R.;BRITO,J.L.S; FERREIRA, L.G. Mapeamento semidetalhado do uso da terra no bioma 
Cerrado. Pesquisa Agropecuária Brasileira, v.43, n.1, p153156. 2008.

SAUSSANA, J.F; ALLARD, V; PILEGAARD, K, et al. Full accounting of the greenhouse gas $(\mathrm{CO} 2, \mathrm{~N} 2 \mathrm{O}, \mathrm{CH} 4)$ budget of nine European grassland sites. Agriculture, Ecossistems and Environment, v. 121, p121-134, 2007.

SHUNKE, R. In: http://www.cnpgc.embrapa.br. Fertbio2004.pdf.

SITTIG, M. Fertilizer industry: processes, pollution controle and energy conservation. Park Ridge: Noyes Data Corporation, 1979. 204p.

SOUZA, D.M.G. de; VILELA, L.; REIN, T.A.; LOBATO, E. Eficiência da adubação fosfatada em dois sistemas de cultivo em um latossolo de Cerrado. In: CONGRESSO BRASILEIRO DE CIÊNCIA DO SOLO, 26., 1997, Rio de Janeiro. Anais. Rio de Janeiro: SBCS, 1997. p.57-60.

TARRÉ, R.; MACEDO, R; CANTARUTI, R.B., et al. The effect of the presence of legume on Brachiaria humidicola pasture. Plant and Soil, v. 234, p.15-26, 2001.

THOMAS, R.J. Role of legumes in providing $\mathrm{N}$ for sustainable tropical pasture systems. Plant and Soil, v.174, n.1-2, p.103-118, 1995.

TISDALE, S. L.; NELSON, W. L.; BEATON, J. D. Soil fertility and fertilizers. 4. ed. New York: Macmillan, 1985. 754 p.

Valentim,J. F.; Carneiro, J. C.; Sales, M. F. L. Amendoim Forrageiro cv. Belmonte: Leguminosa para a Diversificação das Pastagens e Conservação do Solo no Acre. Rio Branco:Embrapa CPAF-Acre, 2001, 14 p. (Embrapa Acre. Comunicado Técnico 43 ).
Vila, F. Quem faz a diferença no sucesso das fazendas. Revista DBO Rural, São Paulo-SP, v.24, n. 293. p. 126, 2007.

VALLE, L. C. S.; SILVA, J. M.; SCHUNKE, R. M. Ganho de peso de bovinos em pastagens de Brachiaria decumbens pura e consorciada com Stylosanthes spp. cv. Campo Grande. In: REUNIÃO ANUAL DA SOCIEDADE BRASILEIRA DE ZOOTECNIA, 38., 2001, Piracicaba. Anais... Piracicaba: FEALQ, 2001. p. 175-176.

VALLIS, I.; GARDENER, C.J. Effect of pasture age on the efficiency of nitrogen fixation by 10 accessions of Stylosanthes spp. Australian Journal of Experimental Agriculture, v.25, n.1, p.70-75, 1985.

Vilela, L.; Martha Jr., G.B.; Barioni, L.G.; Barcellos, A.O.; Andrade, R.P. Pasture degradation and long-term sustainability of beef cattle systems in the Brazilian Cerrado. "Discussion draft presented at the Symposium Cerrado Land-Use and Conservation: Assessing Trade-Offs Between Human and Ecological Needs. XIX Annual Meeting of the Society for Conservation Biology Conservation Biology Capacity Building \& Practice in a Globalized World, Brasília, Brazil. 15-19 July 2005.

VILELA, L.; MIRANDA, J.C.L.; AYARZA, M.A.; SHARMA, R.D. Integração lavoura pecuária: atividades desenvolvidas pela Embrapa Cerrados. Planaltina: Embrapa Cerrados, 1999.29p. (Embrapa Cerrados. Documento, 9)

WINTER, W.H.; WINKS, L.; SEEBECK, R.M. Sustaining productive pastures in the tropics. 10. Forage and feeding for cattle. Tropical Grasslands, v.25, n.1, p.145-152. 1991. 